\title{
Efficacy of AISURE herbal oral liquid feed supplement on conception rate in repeat breeding graded Murrah buffaloes and cyclic graded Murrah buffaloes
}

\author{
P.V. PATIL, U.B. KUMBHAR AND V.M. SALUNKE
}

\begin{abstract}
The present study was conducted in 4 repeat breeding and 4 cyclic graded Murrah buffaloes to see the efficacy of AISURE herbal oral liquid feed supplement on conception rate. AISURE herbal oral liquid feed supplement was drenched to all 8 buffaloes immediate after artificial insemination. Out of 4 repeat breeding buffaloes $2(50 \%)$ were conceived on first AI and $1(50 \%)$ buffalo conceived on second time $\mathrm{AI}$ and one not at all conceived. From the 4 cyclic buffaloes all $4(100 \%)$ were conceived on first AI. 75 per cent overall conception rate was observed. It is observed that AISURE herbal oral liquid feed supplement is useful in increasing the conception rate in buffaloes.
\end{abstract}

KEY WORDS : Herbal liquid feed supplement, Repeat breeding, Cyclic and conception rate

How to CITE THIS PAPER : Patil, P.V., Kumbhar, U.B. and Salunke, V.M. (2014). Efficacy of AISURE herbal oral liquid feed supplement on conception rate in repeat breeding graded Murrah buffaloes and cyclic graded Murrah buffaloes. Res. J. Animal Hus. \& Dairy Sci., 5(2) : 157-158.

Associated Authors':

U.B. Kumbhar and V.M. Salunke, College of Veterinary and Animal Sciences, Udgir, LATUR (M.S.) INDIA

Email :drvms2@rediffmail.com 